\title{
USO DAS REDES SOCIAIS NO ENSINO SUPERIOR: O BLOG E O TWITTER EM FOCO
}

Ana Lucia Farão Carneiro de Siqueira, Jeong Cir Deborah Zaduski, Odair Benedito Francisco, Lívia de Sá Pinheiro, Adriana Aparecida Lima Terçariol, Raquel Rosan Christino Gitahy

Universidade do Oeste Paulista - UNOESTE, Mestrado em Educação, Presidente Prudente, SP. E-mail: anasiqueir@unoeste.br

\section{RESUMO}

Diante do uso das Tecnologias da Informação e Comunicação no contexto educacional, definiu-se como tema deste estudo a utilização de algumas ferramentas que podem beneficiar o processo de ensino e aprendizagem. O objetivo deste artigo foi apresentar duas experiências sobre o uso das redes sociais no contexto educacional do Ensino Superior como alternativas para a promoção de um ensino de qualidade. Para atingir tal objetivo, utilizou-se a construção de um blog e o uso do Twitter abordados a partir de duas experiências vivenciadas, enriquecendo e complementando as informações apresentadas com um levantamento bibliográfico sistematizado. Concluiu-se que quando o professor utiliza as redes sociais para enriquecer o processo de ensino e aprendizagem, de forma colaborativa, há a produção e sistematização do conhecimento, além de promover o fortalecimento das relações interpessoais que são essenciais dentro do contexto educacional, favorecendo a motivação e o engajamento durante a realização das atividades propostas.

Palavras - chave: Redes Sociais, Educação, Blog, Twitter

\section{USE OF SOCIAL NETWORKS IN HIGHER EDUCATION: THE BLOG AND TWITTER IN FOCUS}

\begin{abstract}
In the face of the use of Information and Communication Technologies in the educational context, it was defined as the subject of this study the use of some tools that can benefit the process of teaching and learning. The objective of this paper was to present two experiences about the use of social networks in the educational context of higher education as alternatives for the promotion of a teaching process with quality. To achieve this goal, we used the construction of a blog and the use of Twitter approached from two lived experiences, enriching and complementing the information presented with a systematic literature review. It was concluded that when the teacher uses social networks to enrich the teaching and learning in a collaborative way, there is production and systematization of knowledge, in addition to promoting the strengthening of interpersonal relationships that are essential within the educational context, favoring motivation and engagement during the realization of the proposed activities.
\end{abstract}

Keywords: Social Networks, Education, Blog, Twitter 


\section{INTRODUÇÃO}

O uso das tecnologias da informação e da comunicação (TIC) no contexto educacional ainda encontra discussões polêmicas; de um lado temos diversas pesquisas que apontam os benefícios na sua utilização, como, por exemplo, o relatório da Unesco (2014) sobre o uso das tecnologia móveis na educação; do outro lado temos políticas públicas e pedagógicas que engessam ou proíbem o uso total ou parcial das tecnologias dentro da sala de aula, como, pode-se verificar, por exemplo, a proibição do uso de celulares e tablets em muitas escolas e outras instituições de ensino.

Segundo Moran, "Nunca tivemos tanta chance de aprender juntos como agora". Em entrevista para o site porvir ${ }^{1}$, o pesquisador e professor de comunicação da USP, diz que os princípios de Paulo Freire que norteiam o aprender junto são a colaboração, a troca, a convivência virtual e o compartilhamento de saberes. Segundo Paulo Freire (1987, p. 39) "Educador e educando aprendem em comunhão", ou seja, é necessário que exista diálogo entre professor e aluno, em um ambiente no qual todos são respeitados e têm direto a serem ouvidos, em uma busca constante pela construção em conjunto do conhecimento.

Outro autor que trata da importância do uso de forma crítica e consciente das TIC na educação é Pierre Lévy (2010). O autor defende que vivemos hoje na era da cibercultura e não podemos ignorar a presença das redes sociais em todo o contexto cultural e social, assim como é inevitável a presença das redes sociais na educação.

De acordo com Allegretti, Hessel, Hardagh e Silva (2012, p. 56) a cultura do século XXI está sendo consolidada pela influência marcante da cibercultura, presente desde a década de 70 . As redes sociais através de características como a capacidade exponencial de compartilhamento, a facilidade de acesso, os custos baixos e um ambiente informal e atrativo, motivam cada vez mais pessoas a utilizarem estas ferramentas, principalmente os softwares que permitem uma grande interatividade social como Blogs, Twitter e Facebook (PATRICIO; GONÇALVES, 2010, p. 593).

É nesse ambiente virtual que vários estudos têm encontrado aplicações úteis na educação como: facilitar o compartilhamento de informações envolvendo temas estudados em sala de aula, o estudo em grupo, a divulgação dos mais diversos conteúdos informativos e outras formas para melhorar o relacionamento aluno-aluno e aluno-professor.

\footnotetext{
${ }^{1}$ Disponível em: http://porvir.org/porpensar/paulo-freire-simplicidade-ainda-inova/20140102. Acesso em: 10 jun. 2015.
} 
A web 3.0, também chamada de web semântica, se caracteriza pela interatividade dos usuários da rede, permitindo que estes sejam usuários ativos, autores e criadores dos conteúdos disponibilizados online. Desta forma, tem sido favorecida uma melhor e mais rápida adaptação dos alunos às tecnologias, beneficiando a inteligência coletiva e possibilitando que o aluno seja protagonista em seu processo de ensino e de aprendizagem.

Professores de diversas áreas e dos diversos níveis vêm desenvolvendo propostas de uso das TIC, por meio das diversas redes sociais. Uma das propostas de extensão do trabalho de sala de aula é o uso do Facebook como ambiente virtual de aprendizagem, pois, atualmente é a rede social com maior número de usuários, e a grande maioria deles jovens em idade escolar. Para Mattar (apud SOUZA, 2005, p. 19) "as redes sociais são o habitat da geração que recebemos hoje em nossas escolas e universidades. Portanto, incorporar redes sociais à educação parece um passo instintivo para mantermos o contato com nossos alunos".

Diante desse cenário, o objetivo deste artigo é apresentar duas experiências sobre o uso das redes sociais em sala de aula, mais, especificamente, no contexto do Ensino Superior, enriquecendo as ideias apontadas com estudos realizados na área.

\section{PROCEDIMENTOS METODOLÓGICOS}

Por se tratar de um tema muito abrangente, delimitamos este estudo em dois relatos de experiência. O primeiro deles refere-se à construção de um Blog no contexto educacional como estratégia de ensino e de aprendizagem, desenvolvido na disciplina "Fundamentos da Internet" ofertada no curso superior de Tecnologias em Gestão da Tecnologia da Informação (TI).

A segunda experiência trata de um relato do uso do Twitter como ferramenta de comunicação síncrona, em sala de aula, durante a disciplina "Prática Docente e Novas Tecnologias", ofertada no Programa de Mestrado em Educação. Ambas as experiências são vinculadas a cursos de uma Universidade da rede privada situada em Presidente Prudente/SP.

A fim de enriquecer e complementaras informações aqui apresentadas realizou-se um levantamento bibliográfico sistematizado. A pesquisa bibliográfica reside no fato de permitir ao investigador a cobertura de uma gama de fenômenos muito mais ampla do que aquela que poderia pesquisar diretamente. Esta vantagem se torna particularmente importante, quando o problema de pesquisa requer dados muito dispersos pelo espaço. Além disso, a pesquisa bibliográfica é 
indispensável para a realização de estudos históricos. Desse modo, o procedimento de pesquisa adotado para o desenvolvimento e conclusão do trabalho foi o bibliográfico.

\section{AS REDES SOCIAIS NA SALA DE AULA: O BLOG E O TWITTER}

Os Blogs podem ser explorados, segundo Gomes e Lopes (2007), como recurso pedagógico que tem como característica a disponibilização de conteúdos selecionados pelo professor, contendo links, sínteses de conteúdos, propostas de atividades, etc. Vale considerar que, o aluno também pode se tornar autor nesse ambiente, colaborando com a construção de novos conteúdos. Desse modo, o Blog pode ser utilizado como uma excelente estratégia pedagógica quando o aluno pesquisa, seleciona informações e constrói novos conteúdos, links, sínteses e reflexões.

Sendo assim, o ambiente do Blog pode ir além de um espaço de publicação de informações, mas ser um espaço de interatividade comunicacional, para construção de comunidades que agregam pessoas em torno de diversos assuntos, permitindo discussão e criação coletiva.

A proposta de utilizar o Blog no processo de construção do conhecimento pode ser um trunfo muito simples, já que a criação e publicação pode ser feita por qualquer pessoa com pequeno domínio de uso do computador, sem custo e sem domínio de linguagem de programação. O acesso à internet e cadastro em sites que oferecem este tipo de serviço, alguns gratuitos, é a única exigência.

Durante um bimestre de um semestre letivo o professor responsável pela disciplina de "Fundamentos da Internet" do curso superior de tecnologia em Gestão da TI encontrou uma turma de alunos totalmente desinteressados e desmotivados.

Como estratégia para melhorar o desempenho dos alunos e contemplar o conteúdo do planejamento da disciplina, o professor resolveu utilizar o Blog como um recurso de valorização e ressignificação das aulas. Dividiu a turma em grupos, contendo cinco alunos no máximo e como desafio cada grupo seria responsável por pesquisar, estudar e preparar um seminário de um dos assuntos do conteúdo a ser abordado naquele bimestre. Além de preparar o seminário, os grupos deveriam preparar um texto com o conteúdo do seminário. As datas de apresentação dos seminários foram sorteadas e os grupos iniciaram suas atividades. Após quinze dias da apresentação da estratégia e divisão dos temas iniciou a apresentação dos seminários. 
O professor da disciplina criou um Blog, utilizando o Blogger.com², tendo como título Tecnologias da Informação e Comunicação. Após a apresentação do seminário de cada grupo, o professor disponibilizou autorização para que um dos integrantes do grupo pudesse inserir um post no Blog da turma, adotando como referência o texto que o grupo já havia preparado, anteriormente, a partir do estudo do conteúdo do seminário. Ao final do bimestre todo o conteúdo a ser contemplado pela disciplina estava disponível no Blog que serviu como espaço para os comentários e exposições das ideias dos alunos e de consulta para a avaliação bimestral.

A experiência com o Twitter ocorreu durante a apresentação de um seminário no âmbito da disciplina “Prática Docente e Novas Tecnologias" ofertada no Programa de Mestrado em Educação, conforme mencionado anteriormente, cujo tema era "O uso das Redes Sociais" em Educação, apresentado pelos autores deste artigo.

Nesse momento, foi necessária uma estratégia para permitir um maior engajamento da classe, de forma a incitar o diálogo e a aprendizagem colaborativa. Optou-se então pelo uso do Twitter, como ferramenta potencializadora da comunicação entre o grupo de pós-graduandos e entre alunos e professoras da matéria. Desejava-se, que todo o diálogo ficasse registrado, para, posterior discussão e reflexão.

O Twitter foi escolhido por ser uma ferramenta para comunicação síncrona ou assíncrona, ou seja, permite que a comunicação ocorra em tempo real, quando o emissor envia uma mensagem para o receptor e este a recebe quase que instantaneamente ou, de forma assíncrona, quando o emissor envia uma mensagem ao receptor, e este lê ou responde em outro momento.

Segundo os seus criadores, a missão do Twitter é dar a todos o poder de criar e compartilhar ideias e informações, instantaneamente, sem barreiras. Segundo os dados oficiais da empresa, o aplicativo está disponível em 33 idiomas e conta com 302 milhões de usuários ativos mensalmente e uma média de 500 milhões de Tweets enviados por dia $^{3}$.Vale recordar que, o Twitter tem um limite de apenas 140 caracteres em cada postagem, o que estimula a síntese dos tópicos abordados. Além disso, a possibilidade de usar hashtags ${ }^{4}$ e "retuitar" ${ }^{5}$ faz com que os assuntos mais votados sejam agrupados e fiquem no topo da lista de comentários.

\footnotetext{
${ }^{2}$ Ferramenta gratuita de publicação de blog do Google, para compartilhar texto, fotos e vídeos https://www.blogger.com/start?hl=pt-BR

${ }^{3}$ Disponível em: https://about.twitter.com/company. Acesso em: 10 jun. 2015.

${ }_{5}^{4}$ hashtag é o símbolo \# utilizado antes de uma palavra ou frase que serve para agrupar ideias ou conceitos.

${ }^{5}$... Retweet ou retuitar significa interagir ou responder ao comentário (tweet) de outra pessoa. Quanto mais retweets um comentário tiver, mais alta será a sua posição na página do usuário do Twitter.
} 
A escolha de efetuar a comunicação utilizando o Twitter durante a apresentação do seminário teve como objetivo além de apresentar uma das formas de usar a tecnologia a favor da educação, permitir que a apresentação do seminário fluísse sem interrupções orais, pois as perguntas eram feitas por escrito na página que o grupo criou no Twitter através do perfil @grupoweb30, ou através do uso da hashtag \#grupoweb30.

Esta estratégia permitiu que o grupo finalizasse a apresentação dentro do horário proposto, sem, no entanto, diminuir a quantidade e a qualidade das interações, pois os alunos e professoras escreviam seus comentários e sugestões no Twitter, utilizando smartphones e notebooks e, os componentes do grupo, que não estavam apresentando no momento, também interagiam, convidando os colegas a refletir sobre os assuntos abordados e dialogando pontos críticos dentro do conteúdo proposto.

Em uma hora e meia de apresentação, foram mais de 140 comentários, ou seja, mais de 1 comentário por minuto, tudo registrado e salvo, o que possibilita uma abordagem posterior dos assuntos mais pertinentes ou dos que trouxeram dúvidas e necessitam de um maior aprofundamento.

O uso desta abordagem mostrou-se muito útil e pertinente, tanto para os participantes do grupo quanto para os alunos e professoras, pois o Twitter é uma ferramenta de fácil acesso, com uso gratuito e intuitivo. Um exemplo disso é que a maioria das pessoas envolvidas nesta experiência não tinha ou não acessava o Twitter há muito tempo e, em poucos minutos todos conseguiram criar ou acessar uma conta no Twitter, que inclusive permite o acesso sem a necessidade de baixar o aplicativo.

\section{RESULTADOS E DISCUSSÃO}

A utilização do Blog foi um grande avanço e alcançou o objetivo proposto. O professor pôde perceber o engajamento e interesse dos alunos durante todo o bimestre. O Blog permitiu uma construção coletiva, valorizando a interação e propiciando o desenvolvimento dos alunos, de forma colaborativa.

Vygotsky apud Mantovani (2005, p. 12) comenta que:

O trabalho em colaboração com o outro, enfatiza a zona de desenvolvimento proximal (ZDP) que é "algo coletivo" porque transcende os limites dos indivíduos. A aprendizagem acontece através do compartilhamento de diferentes perspectivas, pela necessidade de tornar explícito seu pensamento e pelo entendimento do pensamento do outro mediante interação oral ou escrita. 
A utilização do Blog neste contexto o transformou em mais do que um recurso pedagógico, mas em uma oportunidade para o experimento de uma nova estratégia de ensino e de aprendizagem, na qual o papel do professor e do aluno pôde ser ressignifcado, estimulando à pesquisa e enriquecendo à elaboração dos seminários. . O professor tornou-se mediador da pesquisa e do conhecimento e os alunos não foram meros receptores, mas coautores da sua aprendizagem com as atividades de pesquisa, seleção, análise, síntese e publicação no Blog para construção do conhecimento.

Os weblogs abrem espaço para a consolidação de novos papéis para alunos e professores no processo de ensino-aprendizagem, com uma atuação menos diretiva destes e mais participante de todos. (MORAN, 2013, p. 41)

Já o resultado da experiência com o uso do Twitter foi muito significativo e todos os participantes envolvidos consideraram a experiência satisfatória, pois houve muita interação entre os autores, as professoras e os demais alunos pós-graduandos. As discussões iniciadas, virtualmente, a partir do Twitter, de forma síncrona, durante o desenvolvimento do seminário pelo grupo responsável foram aprofundadas em sala de aula, após o término da apresentação.

Com essa experiência em sala de aula, verificamos que o Twitter, por ser uma ferramenta que permite a interação, por meio da escrita, sendo utilizado de forma síncrona, possibilitou um grande engajamento dos pós-graduandos na discussão proposta. Mesmo àqueles mais tímidos, se posicionaram, efetivando sua participação na aula.

\section{CONSIDERAÇÕES FINAIS}

Com este relato e estudo das temáticas abordadas, concluiu-se que, quando o professor utiliza as redes sociais para enriquecer o processo de ensino e de aprendizagem, em um ambiente colaborativo, em que os sujeitos deste processo (aluno/professor) desempenham os seus papéis, de forma ativa, o conhecimento é produzido por todos os envolvidos.

Além do mais, a utilização desses recursos promove o fortalecimento das relações interpessoais, uma vez que cada envolvido no processo de ensino e de aprendizagem deve ter clareza do seu papel para com o outro, na realização das atividades propostas em grupo. No caso do Blog, todos os participantes foram responsáveis pelas leituras e comentários sobre os textos produzidos pelos grupos. 
O uso do Twitter como estratégia para motivar os participantes do seminário permitiu com que os pós-graduandos se sentissem motivados e engajados nas discussões propostas, com as interferências pontuais dos integrantes do grupo do seminário, o que gerou, ao final da atividade, colocações instigantes, evidenciando que é possível criar estratégias simples e motivadoras para ensinar e aprender, por meio das redes sociais, tanto no contexto da graduação, quanto na pósgraduação.

\section{REFERÊNCIAS}

ALLEGRETTI, Sonia Maria Macedo; HESSEL, Ana Maria di Grado; HARDAGH, Claudia Coelho; SILVA, José Erigleidson. Aprendizagem nas redes sociais virtuais: o potencial da conectividade em dois cenários. Revista CET, vol. 1, no 2, abril 2012. São Paulo

FREIRE, Paulo. Pedagogia do oprimido. 17.ed. Rio de Janeiro: Paz e Terra, 1987

GOMES, Maria João; LOPES, António Marcelino. Blogues escolares: quando, como e porquê?

Disponível em < https://repositorium.sdum.uminho.pt/bitstream/1822/6487/1/ gomes2007.pdf> Acesso em: 02 de junho de 2015

LÉVY, Pierre; tradução Carlos Irineu Costa. Cibercultura. São Paulo: Editor 34. 3o edição 2010.

MANTOVANI, Ana Margô. Weblogs na Educação: Construindo Novos Espaços de Autoria na Prática Pedagógica. Disponível em < http://www.labin.unilasalle.edu.br/infoedu/blog pedagogico/textos/weblogs_educacao.pdf >. Acesso em: 02 jun. 2015.

MORAN, José Manuel. Integrar as tecnologias de forma inovadora. In: MORAN, José Manuel. Novas Tecnologias e Mediação Pedagógica, Papirus, 21a ed 2013, p. 36-46. Disponível em:

<http://www.eca.usp.br/prof/moran/site/textos/educacao inovadora/utilizar.pdf > - Acesso: 02 jun. 2015.

PATRÍCIO, Maria Raquel; GONÇALVES, Vítor. Facebook: rede social educativa? In I Encontro Internacional TIC e Educação. Lisboa: Universidade de Lisboa, Instituto de Educação. p. 593-598, 2010. ISBN 978-989-96999-1-5 - Disponível em:

<https://bibliotecadigital.ipb.pt/bitstream/10198/3584/1/118.pdf> - Acesso: 02 jun. 2015

SOUZA, Adriana Alves Novais. O facebook como ambiente de aprendizagem: uma analise da práxis presencial mediada pelo conectivismo pedagógico. 2015. 93 f. Dissertação (Mestrado em Educação) Universidade Federal de Sergipe, São Cristovão, Sergipe. 